\title{
LA EDUCACIÓN RELIGIOSA DESDE LOS CULTOS MINORITARIOS: EL CASO PARTICULAR DE LOS HARE KRISHNA EN LA CIUDAD DE MADRID
}

\author{
Néstor Nuño Martínez \\ Universidad Complutense de Madrid
}

http://dx.doi.org/10.5209/rev_NOMA.2012.v36.n4.42315

\begin{abstract}
Resumen.- Debido al poco apoyo en materia educativa que las religiones minoritarias tienen por parte del Estado español, estas religiones ponen en marcha diferentes tipos de estrategias educativas para sus fieles. En este artículo se analizan desde una perspectiva antropológica las diferentes estrategias educativas de carácter no institucional que se programan en un templo que el culto Hare Krishna posee en la ciudad de Madrid, poniendo de manifiesto cómo esas actividades de carácter educativo que el consejo rector del templo propone están cargadas de significados e intereses diversos que son construidos por los diferentes sujetos que acuden a ellas (tanto devotos del culto como sujetos que no guardan relación con el mismo) y el propio consejo rector; un análisis que además puede ser empleado para el estudio de dimensiones religiosas y culturales complementarias como pueden ser los procesos de conversión o los sentidos de la alimentación.
\end{abstract}

Palabras clave.- educación, religión, conversión, cultos minoritarios, creencias, resignificación

\section{Religious education from minority cults: the case of the Hare Krishna in Madrid's city}

\begin{abstract}
Due to the little support in education that the spanish state brings to minority religions, these religions launch different kinds of educative strategies for their faithful. In this article there are analized through an anthropological approach different non-institucionalized educative activities that are launched from a Hare Krishna temple in the city of Madrid, showing how these activities that the temple's council proposes are loaded with a wide range of different meanings and interest that are builded by the subjects who come to them (both devouts and individuals that has no relation with it) and also the temple's council; an analisys that also can be used to the study of other complementary religious and cultural dimensions such as conversion processes or feeding interpretations.
\end{abstract}

Keywords.- education, religion, conversion, minoritary cults, beliefs, resignificance

\section{INTRODUCCIÓN}

En este artículo plasmaré distintas cuestiones, interrogantes y aspectos varios que he ido recogiendo durante el trabajo de campo y el análisis de los datos que venido realizando desde octubre de 2011 en un templo de la comunidad religiosa Hare Krishna en la ciudad de Madrid y otro situado en la localidad de Brihuega, provincia de Guadalajara (aunque en este artículo me centraré en el trabajo realizado en el de Madrid). 
Antes de pasar al artículo "al uso", creo necesario destacar que el conjunto de ideas que plantearé a lo largo del artículo no deben ser tratadas como conclusiones cerradas en tanto que aún sigo realizando el trabajo de campo, y por lo tanto podrían ser reformuladas en el futuro (en tanto que mi investigación vaya avanzando).

Partiendo entonces de esta premisa, es necesario remarcar y explicitar la diversidad de técnicas utilizadas durante dicho trabajo de campo para, de esta forma, dar una primera credibilidad y justificación a las ideas, hipótesis y conclusiones que desarrollaré a lo largo del estudio. Respecto a este aspecto, el trabajo de campo se ha centrado en observaciones de carácter continuado en un espacio concreto (el templo Hare Krishna) en las diversas actividades que se detallarán a lo largo del artículo, entrevistas en profundidad a agentes sociales que acuden de manera regular al templo y que mantienen diversos y variados tipos de relación y lazos con la comunidad Hare Krishna y encuestas de carácter cerrado a sujetos que acuden al templo de forma no continuada o esporádica pero que, a su vez, plantean una visión concreta de las actividades que se realizan en el mismo.

A la hora de estructurar este artículo, comenzaré con una aproximación a este objeto de estudio (la educación religiosa) para mostrar la relevancia del mismo, el contexto actual en el que se enmarca mi trabajo de campo y, a su vez, los puentes que pueden construirse con la subdisciplina de la antropología de la educación a la hora de plantearse qué aspectos de la realidad social pueden tomarse en consideración.

Una vez haya dado cuenta del por qué es interesante abordar un tema de este calibre, pasaré a exponer un análisis sobre las diversas herramientas y estrategias educativas que se articulan en el templo Hare Krishna, detallando su contenido y la relación existente entre ellas.

Por último, plantearé un análisis comparativo, entre las diversas herramientas educativas que se habrán expuesto para, primero, justificar la razón de mis clasificaciones y, también, para dar cuenta y destacar cómo la propia idea de educar tiene distintas interpretaciones, valoraciones, significados y finalidades para la propia institución que, de alguna manera, "organiza" dichas actividades $y$, al mismo tiempo, para los propios sujetos que acuden a dichas prácticas, mostrando cómo no solo existe una idea de lo que es educar si no que, al mismo tiempo, puede entenderse como un proceso dinámico de reestructuración constante en el que confluyen distintas visiones que confluyen en una misma actividad.

\section{LA EDUCACIÓN RELIGIOSA: PRIMERAS CONSIDERACIONES TEÓRICAS.}

Antes de pasar a exponer los planteamientos etnográficos, es necesario tener presente una aproximación teórica que pueda servir para, por un lado, entender mejor cómo dicho trabajo etnográfico ha sido enfocado y guiado hacia unos fines concretos y, por otro, reconstruir teóricamente nociones a priori disociadas como las de religión y educación.

Tomando en consideración la idea acuñada por Ghunter Dietz (Dietz, 2008) de que la transición a la democracia en España no supuso una transición hacia la 
diversidad religiosa, puede asegurarse que actualmente en el Estado español existe un marco legislativo en el cual, si bien se reconoce la libertad religiosa, los supuestos derechos de educación religiosa religiosa en las centros públicas (Art. 27.3 de la Constitución española de 1978; Art. 2 de la Ley Orgánica 7/1980 de Libertad Religiosa) entran en contradicción con la realidad actual y la hegemonía e influencia tradicional que la religión católica ha tenido ( $y$ aún tiene) en la propia construcción del Estado español (Contreras Mazaíro, 2011), lo que a su vez ha marcado que otras religiones hayan sido prohibidas durante largos periodos históricos o incluso estigmatizadas en periodos de tiempo no tan lejanos (Dietz, 2008; Prat, 2001).

Teniendo en cuenta este contexto particular en el que se encuentran las minorías religiosas en España, en donde la educación institucional de la religión se limita a la religión católica (o como mucho, a aquellas religiones consideradas como "mayoritarias"), estas otras religiones "minoritarias" se encuentran diseminadas dentro de un amplio espacio público en el que articulan, diseñan y ponen de manifiesto diferentes estrategias de carácter educativo para promover su propia doctrina religiosa, una realidad social que no siempre recibe el tratamiento más adecuado y sobre la que a veces se tiende a dar visiones confusas y simplificadas de dichas minorías religiosas (López García / Ramírez Fernández / Herrero Galiano / Kirhlani / Tello Weiss, 2007).

Es importante destacar a este respecto cómo esta visión de la religión como "estrategia educativa" choca con las propias concepciones de religión que se han construido tradicionalmente en los países industrializados (Morris, 1987, 2009; Ardèvol y Mudilla, 2003; Cantón, 2009) y que, a partir de los años 60 del siglo $X X$ fueron paulatinamente superándose con el surgimiento y el establecimiento de los "nuevos movimientos religiosos" (Heelas, 1996; Heelas y Woodhead, 2000).

En este contexto de diversidad religiosa (Vallverdú, 2001b), en donde en un mismo espacio público entran en juego diversas doctrinas de principios y tradiciones tan variadas, resulta complejo dar una definición genérica de lo que podría entenderse como religión, y mucho más si hablamos del caso particular de los Hare Krishna - ya que a través de mi propia investigación he podido desentrañar cómo en el culto se entremezclan visiones colectivas y individualizada de un mismo hecho religioso-, por lo que incluso en un contexto tan concreto como en el que he realizado mi trabajo de campo, existen y coexisten diversas formas de entender y de dar sentido a un hecho religioso a priori heterogéneo, poniendo de manifiesto la complejidad teórica a la hora de dar cuenta de todas estas formas de entender la religiosidad desde un posicionamiento ostentivo.

Lo que sí que es cierto, es que algunas definiciones "clásicas" de la idea de religión (Geertz, 2005:89-113) pueden servir para dar cuenta (a pesar de las propias limitaciones de carácter abstracto que el definir la religión como sistema de símbolos que plantea que "todo puede ser construido como símbolo religioso") de cómo la dimensión religiosa es un elemento central en la construcción de una gran diversidad de culturas a lo largo de la historia en tanto que no solo aportan una determinada respuesta a incógnitas de carácter existencial (esa "esencia última de la religión" que en un preocupó a filósofos y 
científicos sociales como Hegel, Marx, Feuerbach, Durkheim, Lévy-Bruhl, Tylor o Frazer) sino que la propia magnitud de su doctrina sobrepasa incluso el campo propiamente religioso y entra de lleno en el propio orden social: "la religión es sociológicamente interesante no porque, como sostendría el vulgar positivismo, describa el orden social [...] sino porque, lo mismo que el ambiente, el poder político, la riqueza las obligaciones jurídicas, los afectos personales, lo modela" (Geertz, 2005: 113), poniendo de manifiesto formas de comportarse, integrarse o de relacionarse dentro de la cotidianidad.

Teniendo en cuenta esta dimensión del fenómeno religioso como un conjunto de formas normativas que transmuta la propia concepción de la religiosidad y que entra de lleno en cuestiones de carácter moral, conductual y prescriptivo, es entonces relevante el plantearse hasta qué punto la educación en materia religiosa es una problemática sobre la que es necesario indagar, y más teniendo en cuenta (como ocurre en el caso de los Hare Krishna) cuando ese tipo de educación contrasta, culturalmente hablando, con la educación católica tradicional.

A la hora de abordar ahora un análisis teórico sobre la educación en materia religiosa, creo esencial tomar en consideración algunos enfoques que la antropología de la educación ha puesto de manifiesto en el estudio de los procesos educativos en contextos de carácter más institucionalizado. Si bien el contexto en el que he desarrollado mi trabajo de campo difiere abiertamente con el planteado en las diversas teóricas al respecto de la antropología de la educación, es interesante tomar en consideración distintos enfoques y perspectivas a la hora de "orientar" la propia observación y el análisis en un contexto como el de un templo Hare Krishna.

Dentro de la gran cantidad de material que la antropología de la educación ha producido, he decidido centrarme algunos de ellos que ponen de manifiesto cómo no solo es importante centrarse en un análisis de las propias instituciones escolares, sino que también es necesario hacer énfasis en el papel de los sujetos que participan en dichos procesos como individuos con ideas, inquietudes y finalidades concretas que continuamente dan sentido y resignifican la propia "oferta educativa" planteada por las instituciones, acomodándola a unos intereses personales o grupales y a unas formas concretas de entender e interiorizar lo que se está "enseñando" en cada momento (Ayala y García García, 2009; Giroux, 1985; Willis, 1988, 1993; Wolcott, 1993; Lahire, 2004).

Teniendo en cuenta todo lo analizado anteriormente, podría resumirse esta primera parte del artículo indicando que, en la medida en que todo culto religioso necesita articular mecanismos para promover su reproducción y expansión, es relevante entender estos mecanismos como "procesos educativos" en tanto que con ellos se busca promover una serie de formas de pensar, sentir y actuar que son útiles tanto para comprender y dar sentido a las propias lógicas del culto religioso como para ser aplicadas al resto de ámbitos de la vida social de los agentes. Al mismo tiempo, a pesar de tomar en consideración los propios intentos que pueda realizar el culto religioso por llevar a cabo estas prácticas, también es necesario (en el caso particular en el que he centrado mi trabajo de campo) dar cuenta de la agencialidad de los sujetos en la interiorización y puesta en práctica de esas lógicas religiosas y, al 
mismo tiempo la influencia que los mismos pueden ejercer en la propia institución en cuanto a la creación o modificación de la oferta educativa en función de sus propias necesidades e inquietudes, dando lugar a un diálogo directo, continuo y bidireccional entre los sujetos sociales y la "institución" religiosa.

Quizás estos planteamientos teóricos no sean extrapolables al estudio de otros grupos religiosos, ya que el caso particular que planteo tiene unas particularidades concretas que se irán detallado posteriormente. Sin embargo, ya se ha comentado anteriormente que esta aproximación teórica también es una herramienta para poner al lector en el "contexto" del artículo, ya que todos estos aspectos expuestos se irán concretando en las siguientes partes del artículo, dando cuenta de todo este marco teórico a través del trabajo de campo que se ha venido realizando.

\section{LA EDUCACIÓN EN UN TEMPLO RELIGIOSO: EL CASO DE LOS HARE KRISHNA}

A la hora de intentar abordar la problemática de estudiar los procesos educativos en un contexto no institucionalizado, el primer obstáculo al que tuve que hacer frente fue el de delimitar cuáles eran los márgenes y características de este modelo educativo.

El motivo de esta problemática se debió principalmente a que este tipo de prácticas que se vienen realizando en el templo tienen un carácter marcadamente informal (a pesar de que guarden una lógica estructurada, que analizaré posteriormente) en comparación con un sistema formal de enseñanza de la religión como puede ser la que plantea una institución como la escuela algunas actividades educativas no son fijas ni continuas en el templo (muchas veces el que se realicen o no depende de que el devoto/a se encuentre en la ciudad, por lo que entre sesión y sesión puede haber una separación temporal de incluso meses), en todas las actividades la asistencia es libre, por lo que no existe un control de asistencia, el número de sujetos que acuden a la misma pueden variar notablemente de semana a semana, etc.-

Por lo tanto, vi necesario el hecho de delimitar la gran variedad de actividades que se realizaban en el templo y que podrían tener una finalidad educativa en función de diversos criterios, facilitando de esta forma, el propio análisis de las mismas.

\subsection{LOS TIPOS DE ACTIVIDADES EDUCATIVAS EN EL TEMPLO}

A la hora de pasar a clasificar las diversas actividades educativas que se dan en el templo, es importante destacar que, por un lado, existen distintos canales a través de los cuales los Hare Krishna publicita actividades que se realizan en el templo (carteles en el propio templo, páginas Web y cuentas en redes sociales como Facebook y Twitter, el boca a boca, etc.), y por otro, que también hay actividades en el templo que, a pesar de tener un carácter educativo, su realización es puntual y no continua. Por lo tanto, para establecer las clasificaciones entre los tipos de actividades educativas me he basado en dos criterios fundamentales: que sean publicitadas de manera pública y, por lo tanto 
la información sobre las mismas y el acceso a las mismas sea libre, y también que se vengan realizando por un periodo de tiempo de como mínimo tres meses.

El por qué elegir estos dos criterios y su correspondiente arbitrariedad se ha debido principalmente a la necesidad de concretar la clasificación para centrarme en aquellas actividades que he podido observar de forma continuada durante largos periodos de tiempo y de forma regular, y que por lo tanto han seguido una estructura bastante estable. De esta forma, he pasado por alto determinadas prácticas que, si bien tienen o tenían un carácter educativo, actualmente ya no tienen lugar o, por otro lado, se llevan realizando desde hace relativamente poco. Abordaré estas prácticas de manera breve en las propias conclusiones del artículo.

Teniendo esto presente, los tipos de actividades educativas que se realizan en el templo podrían dividirse en tres tipos, dependiendo principalmente al tipo de sujetos que acuden a ellas, su estructura y su discurso. Estas son: las clases destinadas a niños, las clases destinadas a devotos Hare Krishna y las clases destinadas a gente que, o bien no tiene contacto, o está comenzando a contactar con el culto.

Para entender el por qué de esta clasificación y, al mismo tiempo, las particularidades de cada clase, es necesario pasar a analizarlas individualmente a través de determinados aspectos concretos de cada una de ellas.

Sin embargo, antes de pasar a la propia descripción de las categorías acuñadas, creo necesario el describir de manera breve el espacio en el que estos tres tipos de actividades se realizan, ya que no solo el espacio es el mismo, sino que el propio lugar es relevante a la hora de comenzar a desentrañar en qué consiste la educación religiosa para el culto Hare Krishna.

Como planteó Balandier (1994), en los espacios de carácter religioso, se interrelacionan funciones manifiestas (propias de cada culto religioso) con funciones latentes (que tienen un contenido político), lo que hace que dichos espacios deban ser considerados también como políticos en donde se producen procesos de socialización, intercambio e integración.

En mi caso concreto, he podido dar cuenta de que según la propia forma en la que son dotados de significados y distribuidos espacial y temporalmente los espacios del templo, pueden cumplir distintas funciones educativas muy diversas.

Para comenzar a justificar el por qué de estos planteamientos, es necesario centrarse en el análisis de lo que vendría a ser el "aula" del templo. ${ }^{1}$

1 A pesar de que hay otros espacios en el templo, en este artículo me he centrado en el análisis de este espacio que he denominado el "aula" del templo. Esto no quiere decir que el análisis del resto de los espacios y la interrelación entre ellos y los sujetos que los transitan no sea relevante, pero para el caso concreto de análisis en el que he centrado este artículo he determinado el no tomar en consideración esos otros espacios con el fin de no desviar la atención del lector y, al mismo tiempo, dotar al hilo argumental de mayor fluidez y dirección. 


\subsection{EL ESPACIO DEL “AULA" DEL TEMPLO}

Para comenzar con la descripción, el "aula" podría describirse como una sala cerrada, con una entrada sin puerta -a la cuál se accede bajando unas escaleras desde el piso principal del templo -, y sin ventanas al exterior (exceptuando unos pequeños respiraderos que dan a la calle, pero que por su inclinación y su altura no son visibles a no ser que uno se coloque justo debajo de ellos).

Una vez se accede a la sala, se pueden observan diversos elementos que podrían parecer "análogos" a los existentes en el aula de una escuela institucionalizada: una pizarra de pequeñas dimensiones, una estantería con libros, unos instrumentos musicales apilados en otra estantería o en el suelo (uno o varios Mridanga $^{2}$, unos cuantos pares de crótalos y un pequeño armonio) o una pequeña palestra plegable en donde se sienta la persona encargada de dar la clase.

Al mismo tiempo, es un espacio diáfano (no hay sillas ni tampoco mesas) y únicamente se observan unas colchonetas de dimensiones cuadrangulares apiladas en la esquina izquierda de la sala.

Esas colchonetas se usan para sentarse, y son desapiladas en la medida en que su uso es requerido por los sujetos que acuden a las actividades que se realizan en el "aula". Podría decirse que no existe un sitio específico en donde estas colchonetas deban colocarse (se esparcen sobre el suelo, ocupando la sala de manera amplia y sin una regularidad aparente), ni tampoco unos sitios "fijos" que deban estar siempre ocupados por la misma persona (ya que según mis observaciones, el número de asistentes a las clases no es fijo -el acceso a las mismas es libre-, no se sigue un "programa docente" propiamente dicho en el que existan unos objetivos a cumplir y las personas asiduas no siempre se sientan en el mismo sitio $^{3}$ ).

Continuando con la descripción, a la derecha de la sala (según se entra de frente a la sala), hay un pequeño arco de madera con unas cortinas que guardan tras de sí el altar del templo. La explicación de por qué se realicen las actividades de carácter educativo en el mismo espacio en el que se encuentra el altar del templo guarda estrecha relación con las prácticas que realizan los Hare Krishna como culto de tradición bhakti (Morris, 2009), aspecto sobre el que se profundizará más adelante.

Justo pegado al altar (en la pared izquierda según se mira el altar de frente), se encuentra un pequeño espacio destinado a una palestra plegada sobre esa pared izquierda. Este es un espacio destinado principalmente al gurú o a aquel sujeto encargado de dar las clases. Justo a la izquierda de esa palestra (situándose en frente) se encuentra la pizarra y estanterías formadas por baldas horizontales de varios niveles, que continúan hasta casi llegar al final de

2 Tambor indio utilizado tradicionalmente en la zona india de Bengala. Tiene dos parches, se toca con las palmas y dedos de las manos y es un instrumento que se usa para acompañar el canto de mantras.

3 Estos aspectos se detallarán más profundamente en las secciones 4. a 7.1.2., mostrando cómo, indirectamente, son los propios sujetos los que van articulando y redefiniendo su propia posición en el espacio dependiendo de sus expectativas e intereses dentro del propio culto religioso. 
esa pared izquierda.

A pesar de que el espacio del aula podría considerarse como "transitado" en tanto que la gran mayoría de las actividades que se realizan diariamente en el templo tienen lugar en este espacio concreto, su distribución no ha variado de forma drástica -sólo se varían algunos elementos de manera puntual: más o menos instrumentos musicales, elementos dentro del altar, etc., pero por lo demás la distribución se mantiene inmutable - durante la realización de mi investigación de campo y, según los testimonios de mis informantes, esto se ha dado a lo largo un periodo temporal más prolongado. Por lo tanto, se podría decir que es una práctica habitual casi desde que se inauguró el templo de Madrid.

Una vez planteado una pequeña descripción del espacio en el que se realizan las actividades, es necesario pasar a centrase en el análisis y descripción de las distintas actividades educativas que tienen lugar en el templo.

\section{EL GURUKULA DEL TEMPLO}

Esta clase está concretamente enfocada a los niños y niñas que acuden al templo con sus padres, y son denominadas por el culto como el Gurukula. Etimológicamente, el término Gurukula proviene del término sánscrito Gurukul , que se asocia a un tipo de escuela de devotos en India y que tiene como características principales que se encuentra en la naturaleza y en la que los alumnos, o familia extensa (el kula), residen acompañado a un gurú (maestro espiritual), el cuál les instruye en aquellas prácticas que un devoto debería conocer en su progreso dentro del estamento religioso (clases de cocina, de sánscrito, de música, de maja mantras, etc.).

Si bien esta vendría a ser una descripción prototípica, el Gurukula que he observado en mi trabajo de campo guarda muy poca relación con esa otra visión del Gurukula a la que he accedido por medio de la consulta de fuentes secundarias y por el testimonio de algunos informantes que tuvieron ocasión de estudiar en Gurukulas en India, gestionados por la organización ISKCON ${ }^{4}$.

Por un lado, en el Gurukula del templo de Madrid, la figura del maestro espiritual es sustituida por mujeres que, si bien están asociadas al culto religioso de una manera directa (normalmente son miembros activos ${ }^{5}$ que gozan de cierta "confianza" con el consejo rector del templo). Por otro, las

4 ISKCON: International Society for Krishna Consciousness (Asociación internacional para la conciencia de Krishna), es una organización creada en 1966 por el fundador e impulsor de movimiento Hare Krishna, Bhaktivedanta Prabhupada, en la ciudad de Nueva York

5 Según los estatus del culto aprobados por el ministerio de justicia, un miembro activo Hare Krishna es aquel que, a pesar de no necesariamente haber sido iniciado en la institución, cumple de forma diaria con algunos de los cuatro principios regulativos del culto: cantar dieciséis rondas, y participa activamente en las actividades del templo. El ser miembro activo también tiene ciertos derechos dentro del culto como es la opción de voto en la asamblea general o el no tener que pagar en el comedor del templo

6 Creo que es importante destacar este aspecto ya que debido a diversas denuncias que tuvo el culto en Estados Unidos relacionadas con abusos sexuales a menores infantiles, en 1990 el culto instauró a nivel un sistema para investigar, denunciar y prevenir incidentes relacionados con el abuso sexual infantil. Uno de los principios para la prevención es el nunca dejar solo a un devoto/a con menores. Siempre tiene que haber más de un adulto en la sala. 
actividades que se realizan en el mismo poco tienen que ver con "acompañar y ayudar" en el día a día en el maestro espiritual. El Gurukula del templo se desarrolla principalmente en el "aula" cada domingo de la semana, encuadrándose en un horario concreto que publicita el templo que va desde las cuatro hasta las seis de la tarde; aunque, a pesar de esta información "oficial", en algunas ocasiones se ha alargado hasta las ocho de la tarde ${ }^{7}$, coincidiendo con el horario de la cena (más adelante explicaré el por qué de que el horario pueda ser alargado a pesar de que los horarios en el templo suelen estar muy regulados), pasando en estos casos, a trasladarse las prácticas del Gurukula a otras instancias del templo, ya que a las seis de la tarde comienzan otras actividades en el "aula", las que están relacionadas con la fiesta de los domingos $^{8}$ (que será explicada más adelante).

Las clases del Gurukula están compuestas por niños y niñas, cuyas edades están comprendidas entre los 3 y 10 años aproximadamente, y determinadas personas adultas que he clasificado como "profesoras" y "asistentes", en la medida en que las primeras interactúan con los pequeños de manera activa (promoviendo las actividades educativas) y los segundos adoptan un rol pasivo, permaneciendo sentados la mayor parte del tiempo y observando la clase, pero no tomando partido en ella.

Seguramente al lector le pueda resultar llamativo el que en la clasificación anterior haya acuñado el término "profesoras", únicamente en femenino. Esto se debe principalmente a que en mis observaciones, únicamente mujeres han adoptado ese rol, y más adelante explicaré de manera breve cómo esa particularidad guarda relación con la propia construcción de género que propone el culto Hare Krishna.

\subsection{LO QUE SE HACE EN EL GURUKULA}

Tras esta primera aproximación a lo que es el Gurukula, creo que la mejor forma de comenzar a explicar qué es lo que se hace en este tipo de clases y, al mismo tiempo, comenzar a dar respuesta a alguno de los interrogantes planteados en la sección anterior, es comenzar recurriendo a la propia descripción y publicidad que el culto hace de la actividad:

"Desde principios de Septiembre [se refiere a septiembre de 2012] se ha implementado en el Templo este programa para que los niños se

En todas las observaciones que he realizado esto se cumplía a rajatabla. No solo algunos padres presenciaban el Gurukula, también otros devotos y en algunas ocasiones las clases eran impartidas por dos mujeres.

7 A partir del mes de Abril de 2013, el horario del Gurukula pasó a realizarse los domingos por la mañana, coincidiendo con el cambio de horario de la fiesta de los domingos, que también se pasó a realizar por la mañana.

8 Esta actividad fue instaurada por el fundador del culto Bhaktivedanta Swami Prabhupada en los años 70, y servía como día de unión entre los creyentes. Es una práctica que también se da en otros templos Hare Krishna, y se propuso que fuera en domingo debido, supuestamente, a que éste era generalmente un día de descanso en las sociedades industrializadas. Existen otras visiones que argumentan que fue una forma de equipararse a otros cultos religiosos que también dan un significado relevante al domingo como el cristianismo, sin embargo ésta es una opinión más compleja de probar debido a la propia ambigüedad de la misma. 
diviertan y participen también de las actividades espirituales de los Domingos. Purnamasi (Titulada en Magisterio de Educación Infantil) y Eva han sido las promotoras de este programa que está teniendo una gran cogida entre las devotas y los niños. Empezó con tres alumnos y ahora hay domingos que llegan a más de diez. Tienen sus propias Deidades, hacen "pujas", aprenden a tocar instrumentos, versos de los vedas, teatro, yoga, etc. Devotas como Sananda y Alicia están impartiendo algunas de estas disciplinas. FELICIDADES A TODOS!!" [El texto en negrita es del autor]. (Hare Krishna Madrid)

En este pequeño extracto quedan reflejados distintas ideas relevantes sobre qué se hace en el Gurukula y, al mismo tiempo, esa construcción de los roles de género que el propio culto plantea.

Analizando el texto, se destaca que el Gurukula es una forma de que los niños participen de las "actividades espirituales de los Domingos". El que se plantee esta idea es relevante en la medida en que, a través de las observaciones que he venido realizando, normalmente los niños que acuden al templo a las actividades de adultos (las que vendrían a ser esas actividades espirituales de los domingos) no participan en ellas, más bien están en el "aula" sentados con sus padre, jugando o durmiendo; o en otras instancias del templo jugando. Por un lado, el hecho de que sean planteadas un cierto tipo de actividades para niños nos hace remitirnos a la premisa con la que iniciábamos el artículo -la necesidad de elaborar estrategias para promover y facilitar la socialización dentro de las lógicas del culto- elaborando, en este caso, actividades "adaptadas" a la propia edad de los participantes.

Esta readaptación de las propias prácticas del culto "adulto" (como pueden ser, la adoración a las deidades, las ofrendas y el conocimiento de la filosofía védica $)^{9}$ se realiza a través del planteamiento de un determinado tipo de actividades de carácter lúdico y dinámico (juegos, canciones, cuentacuentos, manualidades varias, etc.), metodología que contrasta con la que se emplea en el resto de clases del templo que más adelante se detallarán.

Al mismo tiempo, y también en contra de lo que ocurre con las clases del culto "adulto", la estructura de estas clases no es fija, y las actividades van cambiando semana tras semanas. Además, todas ellas tienen un alto componente de improvisación en la medida en que la realización de las mismas atraen (o no) a los asistentes.

En un primer momento, se podría decir que la única finalidad que se pretende con el Gurukula es la que concordaría con el marco teórico propuesto, y un ejemplo de esta readaptación mencionada podría ser la propia actividad del cambio de ropa de las deidades: en el caso de los adultos, es una ceremonia de carácter más bien privado e íntimo que debe realizarse por personas cercanas al culto religioso (por miembros activos principalmente, que además se deben de "comprometer" con la actividades por periodos temporales). Se

$9 \quad$ No se expondrá una descripción detallada de estas y otras prácticas del culto en tanto que, al igual que se argumentó con la descripción del resto de los espacios del templo, supondría una "desviación" dentro de los contenidos que se quieren transmitir con de este artículo. 
realiza un día concreto y a unas horas que suelen variar pero respetando el ritual y también los tiempo. Mientras se realiza el cambio de vestimenta, los sujetos hablan, pero lo hacen en voz no muy alta y en un tono calmado (en testimonios de informantes, la actividad tiene unas fuertes connotaciones sentimentales ya que el realizarla supone una conexión directa con Krishna); es un proceso delicado y azaroso en el que cada traje es manejado y doblado con sumo cuidado.

Por otro lado, en el Gurukula, esta actividad pasa convertirse en un acto totalmente abierto y de carácter informal, en el que todos los niños rodean el pequeño altar que en otras sesiones del

Gurukula se había construido con cartones, cartulinas y lápices de colores. Todos ellos gritan y hasta se empujan unos a otros para poder estar en un primer plano. Las "profesoras" les hablan a los niños indicándoles aquellas prácticas y comportamientos más acordes con lo que vendrían a ser las "adultas", como en un este caso concreto en el que se cambiaba la ropa de las deidades, cuando una de las "profesoras" les indicaba a niños que todos no podían tocar a las deidades y que tenían que hacerlo en silencio. Sin embargo, los niños desatiendían estos principios de cómo se debería cambiar la ropa a las deidades, sumergidos en su particular lucha por ver quién le ponía a las deidades las ropas de cartulina que se habían confeccionando.

Esta misma contraposición entre la visión que el niño tiene de las prácticas y la visión adulta que se busca transmitir, se ejemplifica en casi todas las actividades que se realizan. Por ejemplo, a la hora de enseñar a realizar una puja (adoración a las deidades) las "profesoras" explican paso a paso lo que vendría a ser la visión adulta del mismo, haciendo que los niños intenten imitar cada uno de los gestos, versos y posiciones corporales que deben realizarse en el ritual "adulto", mientras algunos de éstos niños se encuentran dispersos por el "aula" jugando entre ellos, con las colchonetas o subiendo o bajando las escaleras mientras otros atienden e imitan a las "profesoras. Como colofón final, en esta observación las "profesoras" plantearon hacer una puja de verdad, indicando que iba a ser un examen. De alguna forma, esto simulaba una evaluación del aprendizaje de los niños, y hablo de simular porque realmente no fue un "examen" a semejanza al que se puede plantear en una escuela institucionalizada, no se evaluaron unos conocimientos mínimos (no existe, a priori, ningún tipo de objetivo escolar) ni tampoco había una valoración personal de los alumnos; es más, algunos de ellos ni siquiera se inclinaban y pasaban a tumbarse unos encima de otros sin que "las profesoras" les Ilamaran la atención.

Simplemente, el Gurukula debe entenderse como una manera de educar en materia religiosa desde una perspectiva totalmente informal; no se busca tanto el adquirir competencias en materia religiosa como, básicamente, el aproximar a los niños a unas ciertas prácticas que son análogas a las que realizan sus padres en el templo.

Sin embargo, es importante no centrarse únicamente en esta interpretación del Gurukula como proceso educativo -y aquí es donde entra la explicación al por qué de que se realice en unas horas concretas y a veces se alargue hasta las horas que anteriormente se han detallado-, ya que éste debe ser entendido también como una estrategia para facilitar las propias vivencias religiosas a los 
adultos que acude al templo con sus hijos ya que el Gurukula permite que sus pequeños estén entretenidos y no molesten hasta que las clases de adultos terminan, lo que contrasta con las situaciones que se vivían durante la fiesta de los Domingos antes de que comenzara a realizarse el Gurukula, en donde los menores estaban con sus padres durante las clases, moviéndose por la sala, subiendo y bajando las escaleras o llorando, lo que hacía que recurrentemente sus padres tuvieran que centrarse en atender sus necesidades más que en la clase.

Por consiguiente, según el análisis realizado puede indicarse que, si bien el Gurukula como actividad planteada por el propio culto guarda una finalidad concreta que podría asemejarse al marco teórico propuesto, también la propia promoción del mismo en unos horarios concretos que son acoplados con otras clases destinadas a adultos, surgió a raíz de que determinados sujetos que acudían con sus niños pequeños al templo, hizo que el propio culto viera en ello la oportunidad de plantear la actividad y a consolidarla por medio de la publicitación de la misma a través de un discurso que pudiera ser atractivo para los devotos padres como, por ejemplo, el plantear actividades que ellos mismos realizan cotidianamente en el templo pero articuladas y adaptaras desde un conocimiento experto en materia educativa (el que puede aportar, como se menciona en la cita, una titulada en magisterio de educación infantil).

También es importante comenzar a introducir la idea de que el Gurukula, en tanto que es una actividad grupal relacionada con prácticas del culto Hare Krishna, podría sugerir que la visión de la educación que sigue la lógica Hare Krishna es "grupal". En este sentido, se puede plantear la hipótesis de que también las otras actividades educativas del culto estarán enfocadas a buscar una práctica colectiva de la devoción religiosa. Este aspecto se seguirá tratando en el análisis de las otras actividades que se realizan en el templo.

\subsection{LA CUESTIÓN DEL GÉNERO EN LA EDUCACIÓN DEL TEMPLO}

Con el fin de concluir este análisis de la primera actividad educativa del templo, plantearé un breve replanteamiento sobre la construcción de género que manejan los Hare Krishna como institución ( $y$ además plantearé el por qué de elegir solo esta limitada visión en vez de tomar también la visión de los sujetos sociales) a fin de dar respuesta a algunos interrogantes planteados durante el análisis.

De esta forma, se podrá comprender, de manera más concreta, esa particularidad por la cual sólo hay mujeres encargadas de preparar y dirigir el Gurukula.

Brian Morris (2009) ha criticado de manera bastante feroz al culto Hare Krishna por la propia noción de mujer que construye y transmite, tachándolo de un culto "antifeminista" y planteando que "aunque se afirma que no se hace ninguna distinción en base al sexo y que la consciencia de Krishna está al alcance tanto de hombres como de mujeres, se sostiene que <<la constitución física y psicológica de una mujer hace natural que acepte la guía y protección de un hombre>>" (Morris, 2009: 179). Personalmente, no apoyo esta visión de Morris ya que él se centra principalmente en el análisis de las escrituras védicas, no dando relevancia a la propia figura del agente como generador de nociones de 
género $y$, al mismo tiempo, propulsor de cambios estructurales en materia de género, como los que se han venido produciendo en el movimiento Hare Krishna desde aproximadamente la década de los años 70 del siglo XX (Burke, 2007).

Por otro lado, respecto a esta idea de Morris, en mi trabajo de campo sí que he podido dar cuenta de que respecto a esta supuesta construcción inamovible del género, el propio culto Hare Krishna se encuentra dividido entre la modernidad y su propia tradición ancestral en aspectos como, por ejemplo, que una mujer no pueda ser iniciada ${ }^{10}$ o la separación física entre hombres y mujeres ${ }^{11}$. (Burke, 2007). Por otro lado, en varias ocasiones algunos de mis informantes masculinos me han mencionado que aunque las mujeres no puedan iniciarse como los hombres, el que realicen las mismas prácticas y sacrificios religiosos hace que sea como si estuvieran iniciadas, lo que a su vez me hace sugerir una cierta "apertura" hacia entender a la mujer bajo una condición de igualdad frente a las restricciones que pueden plantear las escrituras sagradas. La contrastación de esta "visión masculina" con las propias formulaciones que puedan plantear mis informantes mujeres me ha resultado ciertamente complicado, debido a que el número de mujeres en el culto es menor en proporción al número de hombres, el acercamientos a ellas me ha resultado muchas veces complicado y, además, en algunas entrevistas al sacar estos aspectos las informantes se han centrado en ejemplos propios de las escrituras para justificar esos tipos de prácticas que desde una concepción feminista podrían entenderse como discriminatorias. En tanto que sigo realizando el trabajo de campo, esta es una línea de análisis que sigue abierta y sobre la que tengo planteado indagar más profundamente.

Sin embargo, también es necesario indicar que tanto en is observaciones como en las entrevistas y conversaciones con los informantes de ambos sexos, he podido dar cuenta de la libertad e igualdad que tanto hombres y mujeres disponen a la hora de realizar individualmente las diversas actividades y prácticas rituales en el templo (en contraste también con las propias escrituras sagradas, bastante restrictivas respecto a estos aspectos) relacionadas con la "vía de la devoción" o Bhakti Yoga ${ }^{12}$-las distintas maneras prácticas a través

10 En principio el ritual de iniciación está destinado solamente a hombres, y algunos informantes me reiteraron esta idea. Sin embargo, en Marzo de 2013, durante una breve estancia en IEB (Instituto de Estudios Bhaktivedanta) -finca propiedad de ISKCON situada en Brihuega, Guadalajara - fui testigo de la iniciación de una devota.

11 Según las enseñanzas de Bhaktivedanta Swami Prabhupada, los hombres y mujeres Hare Krishna pueden practicar los rituales del culto en un mismo espacio pero en espacios separados, en contraste con la estricta separación de hombres y mujeres en edificios diferentes que establecen las escrituras védicas. Durante mi estancia en Brihuega fui testigo de esta separación simbólica en un mismo espacio, sin embargo, esta condición no se cumple en el templo de Madrid. Según me han planteado mis informantes el motivo es el poco espacio que hay en el "aula" del templo de Madrid. A mi parecer esto implica una cierta visión flexible y adaptativa de las propias restricciones y separaciones de género que estipula el culto ya que, por ejemplo, a pesar de ser un espacio pequeño se podría plantear su división simbólica u otro tipo estrategia similar. Al mismo tiempo, esta visión tiene distintos puntos de vista (Burke Rochford, 2007).

12 Un tipo de yoga que viene a significar devoción por Dios, y cuya práctica consiste en la meditación y adoración colectiva a Dios mientras se canta su santo nombre, a través de, por ejemplo, el mantra "Hare Krishna Hare Krishna Krishna Krishna Hare Hare, Hare Rama, Hare Rama, Rama, Rama, Hare Hare" , como "mecanismo" para acercase a él y desligarse del mundo material. 
de las cuales un sujeto puede acercarse a Dios_y el "avance" dentro del culto espiritual (que se pone de manifiesto a través de ese ritual de iniciación que observé y también el hecho de que existen mujeres que han tomando los sanniás ${ }^{13}$ ) lo que, de alguna forma, puede servir para seguir fundamentando esta hipótesis de que el culto se muestra en parte "abierto" a estas nuevas reivindicaciones que pueden plantear las mujeres dentro del mismo.

A pesar de que el Bhakti Yoga no es la única vía para "acercarse" a Krishna que contempla la tradición védica, los sujetos sociales atribuían a esta herramienta una gran relevancia frente a otras, y eso se manifestaba en la gran relación que esta práctica mantiene con las diversas actividades que se dan en el templo (las que posteriormente se mostrarán también).

Volviendo a la cuestión del género, según el trabajo que he realizado podría decir que a pesar de estos "alejamientos" de los planteamientos de la tradición védica al respecto de la mujer, en la comunidad que he estudiado siguen dándose determinadas construcciones sociales de carácter tradicional con respecto al papel de la mujer como sujeto reproductor y encargado del cuidado de los niños, y esta idea es promovida a través del propio culto (como, por ejemplo se ha visto en la realización del Gurukula). A este respecto, en la entrevista con algunos sujetos masculinos éstos también me han manifestado este discurso, argumentando que las mujeres deben dedicarse a la crianza de los niños porque "saben más" o "es más natural", en contraposición a otros posicionamientos de carácter más "abierto" (y que también destacan de manera firme) como son el derecho de la mujer a poder trabajar o el reparto equitativo de las tareas del hogar. Estas supuestas contradicciones del discurso ponen de manifiesto una posible nueva e interesante línea de análisis al respecto del parentesco, los nuevos modelos de familia o el género.

Por lo tanto, y a falta de un análisis más profundo al respecto sobre estas cuestiones comentadas, podría decirse que la organización del Gurukula recae en las mujeres frente a los hombres debido a la concepción que estos mantienen ( $\mathrm{y}$ puede que las mujeres también) sobre cuáles son las propias funciones de la mujer, pudiéndose observar estas prácticas en un gran número de situaciones variables en la que hay una interrelación de adultos con menores como, por ejemplo, a la hora de vigilar a los niños en las clases de adultos de los domingos, antes de que comenzara a realizarse el Gurukula , o al dar de comer en las comidas y cenas en los pequeños.

Sin embargo esta supuestamente separación de roles entre hombres y mujeres queda un poco más distanciado en esas otras actividades más relacionadas con los rituales, la cocina o la limpieza, ya que en este sentido son actividades en las que he observado que tanto hombres como mujeres participan de manera cercana y en interrelación.

13 El sanniasa es la cuarta etapa de los áshramas (los periodos de la vida de un hombre según las escrituras védicas) y consiste en que el sujeto abandona a su cónyuge y familia y comienza a peregrinar por el mundo predicando la palabra de Dios. Muchas órdenes hindúes tradicionales no aceptan que las mujeres tomen los sanniás, cosa que en las órdenes occidentales ha ido cambiando. 


\section{L AS CLASES DESTINADAS A DEVOTOS HARE KRISHNA}

Si bien tradicionalmente la educación de los devotos como tal ha recaído en la figura masculina, ya se ha mencionado cómo el culto Hare Krishna ha planteado cambios al respecto. Quizás debido a que eso pueden ser relativamente cercanos en el tiempo, a que el número de mujeres sea menor al de hombre y que además su posible interés de "avance" en el culto se centre en campos distintos como puede ser el Ayurveda ${ }^{14}$ o el Yoga, puede que estos cambios no se perciban abiertamente en el templo de Madrid, ya que la gran mayoría de las clases son realizadas por hombres salvo cuando alguna maestra espiritual está de paso por el templo. Sin embargo, no quiere decir que en un futuro este hecho pudiera cambiar si cambian la realidad social del templo.

Pasando al análisis de las clases para adultos, aunque en el templo no exista una separación formal y física entre las clases que estarían destinadas a gente devota y gente menos experimentada (como, por ejemplo se da en la finca de Brihuega), yo he planteado esta separación entre las clases destinadas a devotos y las clases destinadas a gente que no suele tener relación con el culto atendiendo a que en mis observaciones, entrevistas y conversaciones informales, he encontrado diversos indicios de que los propios sujetos sociales son los que producen esa separación. Quizás en este momento pueda resultar complicado entender el por qué de esta diferenciación que propongo, pero a posteriori, cuando plantee una comparación entre los distintos tipos de clases en el templo y la propia actitud de los sujetos, se dará sentido a esta diferenciación que planteo.

A su vez, planteo una nueva diferenciación en estas clases más destinadas a devotos Hare Krishna atendiendo a esa propia "separación" que mediante su actitud y comportamiento los sujetos plantean. Las clases se dividirían en dos tipos, repartidas en varios días de la semana: las clases de Bhagavad Gita ${ }^{15}$ (los miércoles y viernes a las siete de la tarde $-\mathrm{y}$ que suelen durar hasta las nueve aproximadamente-), y las clases de la fiesta del Domingo. ${ }^{16}$

\subsection{LAS CLASES DE BHAGAVAD GITA}

Estas clases se realizan dos días a la semana en el templo, y podría decirse que su estructura está muy bien delimitada.

Suelen ser dirigidas por un hombre que ostenta una posición de bráhmana ${ }^{17}$

14 El sistema médico tradicional en India.

15 El Bhagavad Gita podría definirse como el "libro de cabecera" de los devotos Hare Krishna . Su origen no se puede concretar, situándolo entre el siglo II a. C. y el siglo V d. C., y está compuesto por 700 versos. En él se encuentran los fundamentos de la filosofía védica, narrados a través de una serie de conversaciones entre Krishna y el guerrero Aryuna a raíz de una batalla en la que este último debe combatir contra miembros de su propia familia y grandes amigos. El análisis que algunos autores realizan del mismo (Morris, 2009) plantean el Bhagavad Gita como un escrito en el que se muestran una serie de preceptos morales dados por Dios y cuya moraleja última es que los hombres deben seguirlos y cumplirlos a pesar de que ello vaya en contra de los propios principios individuales.

16 Cuyo horario, como he mencionado anteriormente, cambió en Abril de 2013. Hasta esa fecha la fiesta de los domingos empezaba aproximadamente a las $18 \mathrm{~h}$ y terminaba sobre las 21:30h.

17 Que pertenece a la casta sacerdotal 
aunque, como ya he mencionado, en algunas ocasiones las han dado mujeres o incluso devotos ya iniciados pero que no ostentaban este título.

Pasando al análisis de la estructura, al comienzo de estas clases se realiza un Bhajan (cantos devocionales), práctica que consiste en recitar distintos mantras en sánscrito mientras se tocan instrumentos musicales. Primero los recita el "sacerdote", que también es el encargado de tocar el armonio, y después el resto de personas de la clase repiten el mantra con la misma entonación. Estas personas pueden dar palmas o también tocar otros instrumentos musicales, normalmente crótalos. El tambor o tambores del "aula", normalmente suelen ser tocadas por personas ya iniciadas que conozcan distintos ritmos, ya que éstos van variando en medida en que la rapidez y la entonación de los mantras va cambiando.

Esta práctica suele durar unos 30 minutos aproximadamente, y su inicio y final la marca el "sacerdote", el cuál regularmente observa un reloj de pared que se encuentra en el "aula".

Después de estos cantos devocionales, se pasa a comentar un capítulo y un verso concretos del Bhagavad Gita, aunque no sigue un orden establecido, sino que la elección de los mismos pasa a depender de la elección del propio "sacerdote".

La estructura mediante la cual se comenta el verso es siempre la misma, y se compone de cuatro partes principales: lectura, repetición, definición y explicación.

La parte de repetición es variable y hay veces que no se da, dependiendo del propio "sacerdote" que esté dando la clase o de los asistentes. Al mismo tiempo, se pueden dar varias variaciones en la parte del "sacerdote".

En la lectura, el "sacerdote" lee el fragmento en sánscrito de manera continua y con una entonación concreta. Lo repite normalmente dos veces, mientras el resto de asistentes sólo escucha. Una de las variaciones que he observado en esta parte es que el "sacerdote" dice una palabra en sánscrito y el resto la repite, repitiendo este proceso con todo el verso $\mathrm{y}$, repitiendo el verso dos veces.

En la repetición, el "sacerdote" invita a los presente de la sala a que también repitan el fragmento en voz alta. La gente que se anima a hacerlo, suele intentar imita la propia imitación y las pausas del "sacerdote" mientras se apoya en la lectura del verso (en sánscrito), que ha sido anteriormente escrito en la pizarra del templo, para que todos los asistentes puedan leerlo.

En la definición, el "sacerdote" pasa a explicar cada uno de los términos del fragmento, nombrándolos primero en sánscrito y después en castellano. Son términos que, a priori, no guardan

relación entre sí, ya que no están estructurados en frases, si no que son palabras inconexas.

Después de cada término la gente de la sala repite las mismas palabras del "sacerdote" intentando imitar su entonación. Normalmente suele repetirse esta parte una o dos veces.

Por último, en la explicación, el "sacerdote" pasa a explicar a los asistentes el 
significado del fragmento en relación con diversos principios de la filosofía védica y concepciones del propio culto

religioso. Esta parte es la más extensa en cuanto a duración, y lo que se dice en la misma guarda estrecha relación con esas premisas sobre la finalidad de las instituciones religiosas en las que se ha

fundamentado y justificado este artículo. Sin embargo, al tener estrecha relación con una de las partes de las clases de los domingos, se analizará más detenidamente al tratar esas otras clases.

\subsection{LAS CLASES DE LOS DOMINGOS}

Según la información que se puede extraer de la página web del templo (Hare Krishna Madrid), las actividades de la fiesta del domingo se dividen en cuatro: Bhajan , Conferencia, Aratik y Prasadam.

Es relevante el hecho de que estas cuatro partes estén en su mayoría nombraras en sánscrito, y más aún si las comparamos con cómo estas actividades eran presentadas a través de tarjetas (por aquella fecha el templo aún no tenía página web) hacia finales de 2011, cuando empecé a realizar mi trabajo de campo: música devocional, filosofía védica, fiesta vegetariana.

El contenido es el mismo, sin embargo, la propia forma de nombrar las actividades me llamó la atención en su día, por lo que en mis observaciones y análisis me planteé ahondar en el por qué de esto, ¿qué importancia podía tener el nombrar las actividades en sánscrito?.

El comienzo de estas clases es bastante similar al de las clases del Bhagabvad Gita, durante aproximadamente media hora se realiza el canto de distintos mantras , que normalmente son dirigidos por un "sacerdote". Sin embargo, una vez terminan, baja un maestro espiritual (que suele variar cada poco tiempo, ya que normalmente los maestros espirituales no están fijos en un templo, sino que viajan predicando la palabra de Krishna) o, en algunas ocasiones (dependiendo de que haya un maestro espiritual o no), otro "sacerdote" que normalmente no imparte las otras clases para devotos, y que a veces suele proceder de otro templo y, tras colocarse en la palestra, se vuelven a cantar otra vez mantras durante un periodo de tiempo comprendido entre los cinco y los veinte minutos (lo que vendría a ser el Bhajan).

Una vez terminan los cantos, el maestro espiritual pasa a recitar un fragmento del Bhagabvad Gita seleccionado previamente, y se repite las mismas partes correspondientes que en las clases de Bhagabvad Gita antes descritas. Esta parte de las actividades dura aproximadamente una hora, tras la cuál pasa a realizarse una ceremonia de Aratik (o adoración de las deidades) en el que una persona se introduce en el altar ofrecer distintos objetos a las deidades (incienso, fuego, agua y flores aromáticas principalmente) para sacar del mismo esos objetos una vez purificados y compartiéndolos con los presentes mientras éstos pasan a realizar un Kirtan (cantos devocionales como los que se hacen en el Bhajan pero, en este caso, se canta más alto y se baila de pie o dando saltos a un ritmo más rápido). Estas dos actividades duran aproximadamente otros unos 30 minutos, y en el caso de Aratik, suele estar realizada siempre por la misma persona, que en el templo de Madrid, durante mis observaciones, era 
una hombre ya iniciado (no así como en Brihuega, donde también observé a una mujer realizando la adoración) que además también se encontraba a cargo de otras labores menores del templo como ordenar el altar o limpiar el mismo (al mismo tiempo, ese hombre va rotando).

Si bien tanto las clases de Bhagabvad Gita como las de los domingos pueden parecer muy similares en su estructura, hay que atender a determinadas variables que he observado y que me han servido como criterios para separarlas en dos categorías distintas. Estas características son el tipo de personas que acuden a las clases y también el contexto del culto en el que éstas se dan. La entrada a estas clases es libre, cualquiera que acuda al templo a esas horas puede acceder a las mismas, sin embargo cabe destacar que el número de personas que acuden a las clases de Bhagabvad Gita suele ser mucho menor y menos diverso que al que acude a las clases de los Domingos.

Esto es debido principalmente a los días en los que se desarrollan los distintos tipos de clase, ya que

entre semana la gente trabaja y tiene más obligaciones y, por lo tanto, acude menos al templo. Por otro lado, en fin de semana la gente suele tener más tiempo y pasa a convertir el templo en un espacio destinado a la familia. Al mismo tiempo, los domingos hay planteadas otras actividades en el templo, como son el Gurukula, (que ya ha sido explicado anteriormente y que surgió como manera de explicar un vacío de actividades del templo destinados a los pequeños que acudían con sus progenitores al templo) y una comida de carácter gratuito para aquellos que han asistido al programa completo. Más adelante se especificará que relevancia puede tener esta particularidad.

\section{LAS CLASES DESTINADAS A GENTE QUE NO SUELE TENER RELACIÓN CON EL CULTO}

Una vez explicadas estas clases destinadas a devotos queda adentrarse en el análisis de la tercera categoría planteada, aquellas clases que están enfocadas para gente que no tiene relación con el culto.

Estas clases se realizan en el templo de lunes a sábado, entre las dos y las dos y media de la tarde (aunque el horario puede variar a lo largo del año, pero se mantiene sobre la misma hora).

La estructura de las mismas se asemeja en bastante medida a las de las clases para devotos ya analizadas, sin embargo tiene una cierta especificidad que permite diferenciarla de las anteriores.

Primero, se realizan unos Bhajan, que son dirigidos por el presidente del templo de lunes a viernes y por el presidente regional del culto los sábados, y que duran aproximadamente unos quince minutos.

Tras ello, hay una pequeña conferencia que dura otros quince minutos y que se puede asemejar bastante a las que se dan en las otras clases pero que, en vez de versar sobre un tema concreto del Bhagabvad Gita, se centra en aspectos de la vida cotidiana y la realidad actual (la crisis económica, la violencia en la sociedad, la necesidad del desapego material, etc.) que son analizados desde la propia lógica del culto religioso. Al igual que pasaba en las otras clases, el 
tema es elegido por la persona que en ese caso vaya a hablar, que siempre coincide con la que anteriormente ha dirigido los Bhajan.

Tras la conferencia hay una comida, que también se realiza de lunes a sábado y en la que los comensales deben pagar una cantidad fija de dinero.

\section{EL POR QUÉ DE LA CLASIFICACIÓN DE LAS ACTIVIDADES SEGÚN A QUIÉN VAYAN DIRIGIDAS}

Ahora bien, después de explicar unas determinadas clases que son destinadas a devotos y las que no, queda contestar a la pregunta, ¿y por qué se podría decir que que unas son destinadas a devotos y otras no? ¿Por qué sujetos que, a priori, no tienen relación con el culto acuden a unas y no a otras?

Para contestar a estas cuestiones es necesario hacer una comparación de los análisis ya realizados, $\mathrm{y}$, al mismo tiempo, plantear un nuevo análisis centrado en los propios detalles particulares de cada tipo de clase y también en la propio comportamiento que los asistentes a las clases tienen durante las mismas.

Comenzando con este análisis comparativo, hay varios elementos que en los análisis han salido a relucir y sobre los que hay que centrar la comparación: la duración de las clases, el contenido de las mismas, las actividades complementarias y los sujetos que dan las clases.

Al mismo tiempo, en este análisis hay que incluir la propia visión de los sujetos que acuden a las actividades. Mediante mis observaciones y encuestas en el templo, he comprobado cómo existe una correlación entre el tipo de sujetos que acuden a las mismas y su propias expectativas dentro del culto y el comportamiento que tienen en dichas actividades. Este último análisis también deberá ser tratado a parte.

Respecto a las dos primeras variables (la duración de las clases y su contenido), se observa una cierta similitud en ambas variables entre las clases de los domingos y las de Bhagabvad Gita; no así con las clases que he denominado como destinadas a sujetos que no tienen que relación con el culto Hare Krishna, en cuyo caso tanto el tiempo como el contenido es distinto.

El por qué de esta diferenciación puede entenderse mediante la lógica de que un devoto integrado dentro del culto va a tener unas intenciones y unas inquietudes de carácter educativo (de carácter más profundo y directamente relacionadas con la filosofía védica recogida en el Bhagabvad Gita) mientras que un sujeto que esté, de alguna manera, "iniciándose" y comenzando a conocer el culto buscará aquellas clases en las que se traten temas más cotidianos desde una perspectiva religiosa pero, al mismo tiempo, de manera más informal y sencilla.

En las observaciones realizadas y encuestas realizadas en el templo esta norma tiende a cumplirse, encontrándome incluso con sujetos que, habiendo acudido por primera vez a una clase de los domingos, la encontraron demasiado "densa" para lo que estaban buscando en ese momento. Esto no quiere decir que la norma se cumpla, ya que hay factores individuales de cada sujeto que influyen directamente (que uno sujeto sólo pueda acudir al templo en un día y a una hora determinada, etc.) pero, por lo general, se suele cumplir esta distinción que los propios sujetos hacen de las clases. 
Al mismo tiempo, a través de las entrevistas realizadas he podido constatar cómo sujetos ya integrados dentro del culto buscan acudir a las clases de Bhagabvad Gita o a la de los domingos en lugar de a las de la semana. En algunos casos debido a que tienen impedimentos laborales o familiares pero en otros, simplemente porque les parecen más "enriquecedoras".

A este respecto se puede justificar el por qué diferenciar estos dos tipos de clases pero, ¿por qué diferenciar también las clases de los domingos y las de Bhagabvad Gita?

Para explicar esta nueva diferenciación es necesario atender a las actividades complementarias y también a los propios sujetos que imparten las clases.

Respecto al primer factor, en la clase del domingo se desarrollan más actividades complementarias a parte de la clase, tanto el Gurukula como el Aratik, el Kirtan o la posterior comida, mientras que en las clases de Bhagabvad Gita algunas veces tras la clase uno de los cocineros prepara dulces para los asistentes, pero nada más.

En cuanto al segundo factor, las clases de Bhagabvad Gita suelen ser impartidas por gente del centro, si bien son "sacerdotes" algunas veces no tienen por qué. Sin embargo, las clases del domingo suelen ser impartidas por gente de fuera del templo y que, en muchas ocasiones, ostenta títulos superiores como el de maestro espiritual.

Volviendo a la lógica de los devotos Hare Krishna, estos hechos pueden ser relevantes. En primer lugar porque, a pesar de que el estudio de la filosofía védica es necesario para el acercamiento a Dios, también lo es la adoración de las deidades, la práctica del Bhakthi-Yoga y la comida ${ }^{18}$, y en segundo porque un maestro espiritual siempre va a tener " a los propios devotos.

En las observaciones y entrevistas que he realizado, he podido constatar como estos planteamientos también se cumplen, siendo la clase de Bhagabvad Gita a la que normalmente tiene menos público (en algunas ocasiones había solo dos personas contando con el sujeto que impartía la clase) pero, eso sí, un público más iniciado en el culto y con distintas inquietudes e intereses al de las clases de entre diario; y la clase de los domingos la más demandada (en muchas ocasiones el espacio del "aula" se ha quedado pequeño y no todo el mundo ha podido acceder al mismo).

Por lo tanto, podría plantearse la idea de que un sujeto que no sea devoto y, al mismo tiempo, no tenga intención de acercarse al culto más allá que por su comida (como suele pasar en las clases de diario según las encuestas y observaciones realizadas), no se centrará en aquellas actividades que se salgan de sus expectativas.

Por otro lado, otros sujetos sociales que tengan otro tipo de ideas, inquietudes con respecto al culto Hare Krishna terminan, tarde o temprano "aventurándose" a alguna de las otras dos clases. En tal caso, estos sujetos eligen (en función de su disponibilidad) las que tienen un mayor número de actividades

18 El centrarse en un análisis detallado de la comensalidad dentro de las lógicas Hare Krishna es un tema que, ciertamente, desbordaría los objetivos propuestos para este artículo pero, sin embargo es importante tener presente esta idea para comprender que exista esta actividad puede ser relevante para un devoto Hare Krishna ya que la alimentación otra de las formas de conectar con Krishna. 
complementarias.

He observado en ocasiones sujetos que normalmente acuden los domingos acuden también entre diario a las clases y a la comida pero, sin embargo, esto no suele ser algo común. Normalmente, a medida que un devoto está integrado y se percibe como integrado dentro del culto, suele acudir a esas otras actividades.

Al mismo tiempo es importante no sólo centrarse en razones únicamente relacionadas con el conocimiento religioso para explicar el por qué unas clases estén más solicitadas que otras, también hay dos factores que he encontrado relevantes: la cuestión económica y la cuestión de cohesión grupal.

En la cuestión económica, todas las actividades del templo son gratuitas salvo las comidas que se dan entre semana, que tienen un precio fijo. Por otro lado, la comida que se sirve los domingos es gratuita, pero tiene ciertas reglas y restricciones.

Las comidas de entre semana van precedidas de la clase, pero no es necesario acudir a la clase para poder después comer, es más, según mis encuestas y conversaciones informales, mucha de la gente que acude al templo entre semana acude a comer ya que es una comida "buena" y "barata" y no está interesada en los cantos.

Por otro lado, los domingos la comida también va precedida por la clase, pero cuando ésta era por las tardes (hasta abril de 2013) se solía cerrar la verja principal del templo sobre las 19 horas para impedir que entrara gente sólo a comer. Este hecho puede guardar relación también con la idea de cohesión grupal que expondré a continuación, pero resulta al menos curioso que en unos casos se haga y en otros no, y puede que sea porque a la fiesta de los domingos, como ya he comentado, suelen acudir principalmente devotos.

Sin embargo, también hay no devotos que acudían los domingos por la tarde sólo a cenar, solo que tenían que estar dos horas esperando, desde que comienza el programa, a que se sirva la cena, lo que a algunos les resultaba "molesto" y "aburrido", por lo que no había muchos sujetos no devotos que tomaran esta opción.

Sí que es cierto que hubo ciertas temporadas en el templo, en el que no se cerraba la verja durante el programa de los domingos, y esto hacía que en esas temporadas hubiera personas que entraban al templo a la hora de la cena, cenando sin la necesidad de tener que asistir a la fiesta del domingo. La directiva del templo, consciente de esto ( $y$ de otros factores que no vienen a colación en este momento), decidió entonces tomar esta medida de nuevo a partir de enero de 2013, un ejemplo más de cómo no solo son los sujetos sociales los que marcan la propia preferencia hacia unas clases, sino que también institucionalmente se fuerza esta diferenciación, ya que de esta manera las fiestas de los domingos pasan a ser actividades específicamente articuladas y modeladas para los devotos, creando en ellas un clima de complicidad entre ellos a la hora de, por ejemplo, hablar y comentar ciertas ideas y aspectos que no comentarían en espacios en donde pudiera haber gente no devota que no estuviera acostumbrada a ese tipo de lenguaje cargado de terminología sánscrita.

Otros ejemplos más de cómo la propia institución religiosa modela esta 
separación de los sujetos en distintas actividades reside en el propio discurso de las conferencias y el cómo se publicitan las actividades.

En lo referente a las conferencias, las que se dan entre diario tienen un discurso que, si bien se estructura desde la propia lógica del culto, no se mencionan aspectos profundos del mismo que sí que aparecen bien remarcados en el resto de clases a las que acuden personas más introducidas en las lógicas del culto y la filosofía védica. Por lo tanto, podría pensarse que la propia institución busca promover esas clases destinadas a gente que no es devota para que, en cierta medida, puedan

sentirse atraídos por un discurso esencialmente crítico con muchos aspectos de la sociedad actual y su materialismo y, según estas personas empezaran a interesarse más por el culto, comenzaría a frecuentar los otros tipos de clases al considerar a las clases para no devotos como demasiado "simples", buscando una justificación más profunda (basada en la filosofía védica) a ese discurso crítico que mantienen los Hare Krishna. Al mismo tiempo, en estas nuevas clases coincidiría con otros devotos con los que compartir inquietudes y opiniones, lo que también ayuda a que el propio agente social pase a moldear su elección e interés por un tipo de clases frente a otras.

Respecto a la propia publicidad institucional de las propias actividades, la forma en la que se dividen las actividades que se dan entre la semana (a través de las tarjetas que los Hare Krishna tienen en su templo o de la propia página web del templo) es en "cantos" y "comedor", y las actividades de la fiesta de los domingos: "Bhajan (cantos)", "Conferencia", "Aratik" y "Prasadam" (Hare Krishna Madrid).

Como se puede observar la propia forma en la que se nombran actividades es prácticamente idéntica, y permite que las primeras puedan ser entendidas por cualquier persona que no tenga relación con el culto mientras que para entender las segundas, es necesario tener conocimientos de determinados conceptos claves para el culto, como es el de Prasadam, un ritual asociado a la ingesta de alimentos, o, en su defecto, conocer a través de algún canal que los domingos a cierta hora, se sirve la comida gratis en el templo (como sería el caso de estos no devotos que sólo acudían a las cenas de los domingos).

Al mismo tiempo, el hecho de que una sea denominada como "clase" mientras que la otra sea una "fiesta" puede que también implique una propia jerarquización de las actividades por parte de la propia institución religiosa.

Como he mencionado también a lo largo del artículo, en Abril de 2013 el horario de la fiesta de los domingos ha cambiado, y a pesar de que no se cierra la verja principal del templo, sí que en la página web se pone un aviso al respecto de la "entrada libre": "Entrada libre con comida incluida para todos los que participen del programa espiritual desde 13:30H. Los que lleguen después podrán disfrutar del comedor aportando un donativo como el resto de los días" (Hare Krishna Madrid). Como se puede observar, es una nueva forma de limitar la separación entre devotos y no devotos, quizás menos agresiva que la que se llevaba anteriormente, pero muestra cómo desde el culto hay una cierto interés en tratar de diferenciar la fiesta de los domingos.

A parte de este aparente énfasis de la dirección del templo por hacer esta distinción, también son los propios devotos los que la ponen de manifiesto esta 
distinción a través de un ideal de cohesión grupal.

En este sentido se podrían distinguir dos elementos cohesionadores, en primer lugar la propia filosofía védica, según la cuál es importante adorar a Krishna en conjunto, fomentando así una propia lógica sobre la importancia de la colectividad, según la cual la unión grupal entre devotos es una de las formas de progresar y apoyarse dentro del mismo grupo, creando vínculos y uniones que pueden servir para fortalecer la $\mathrm{fe}^{19}$.

Y por otro lado, también el hecho de que exista un acto de comensalidad podría ser relevante para esta diferenciación, ya que como bien reflejan Jesús Contreras y Mabel Gracia (Contreras Hernández y Gracia Arnáiz, 2005), la comensalidad puede servir como elemento cohesionador del propio grupo social. Y también, como se ha mencionado anteriormente, las propias visión que los Hare Krishna tienen de la alimentación hacer que, para los devotos, la comida esté cargada de connotaciones religiosas y grupales, al igual que el resto de actividades que se realizan el domingo, lo que nos remitiría a la idea de que todos los factores están interrelacionados y no existe una causa única por la cuál estos hechos sociales se reproduzcan de manera continuada.

Con este breve análisis comparativo ha mostrado cómo, tanto los propios devotos como la propia institución religiosa son los que, por medio de distintas estrategias, van creando estas diferentes categorías de clases en el templo en función de las propias finalidades que cada uno de los sujetos implicados con las mismas pueda buscar, creándose así un discurso bidireccional entre los propios sujetos "alumnos" y la propia institución religiosa, que se pone de manifiesto, por ejemplo, en el hecho antes mencionado de que sólo desde hace unos meses tras las clases de Bhagabvad Gita se ofrecen dulces, ¿podría ser una propia estrategia de la institución para intentar "atraer" a más sujetos a esas clases? Sería necesario continuar con este análisis en el tiempo para ver cómo estas actividades se van modelando y reconfigurando.

\subsection{LOS SUJETOS EN EL AULA}

En el apartado 7. se ha mencionado la necesidad de plantear un análisis de la propia actitud que los sujetos mantienen dentro del "aula" para seguir justificando y al mismo tiempo fortalecer los planteamientos formulados al respecto del por qué de haber planteado esta particular clasificación de actividades.

En este sentido, primero incluiré un pequeño cuadro en donde incluyo los diferentes comportamientos observados $y$, después, plantearé una interpretación más detallada de dichos comportamientos, asociándolos a cada una de las actividades anteriormente descritas, para, de esta forma, ir construyendo y delimitando mis planteamientos de investigación al respecto de cómo se comportan los distintos sujetos en las actividades del templo.

19 En este sentido, en las entrevistas que he realizado esta idea suele ser bastante recurrente en los devotos. Si bien cada uno la entiende de una manera diferente y le da una mayor o menor relevancia en su vida a esta idea de la "religiosidad colectiva", todos ellos argumentan la importancia de la colectividad a la hora de fortalecer las prácticas en el culto y también a la hora de fortalecer la propia conexión individual que cada uno mantiene con Krishna. 


\subsubsection{LOS COMPORTAMIENTOS DE LOS SUJETOS}

En este cuadro incluiré los diferentes comportamientos que he observado en las actividades durante mi trabajo de campo. Si bien en el análisis del Gurukula he hecho una pequeña descripción de los comportamientos de los asistentes al considerarlo como un caso particular, los datos de la tabla podrán aplicarse al análisis del resto de actividades del templo.

A la hora de ordenar la tabla, en las filas he incluido las clasificaciones de devoto y no devoto y en las columnas las diferentes "reacciones" que he observado a cada una de las actividades que se han descrito en este artículo. También algunos gestos se dan en el momento de entrar y salir de la sala, así que también los he incluido en tanto que creo que son relevantes para entender la diferenciación entre devotos y no devotos.

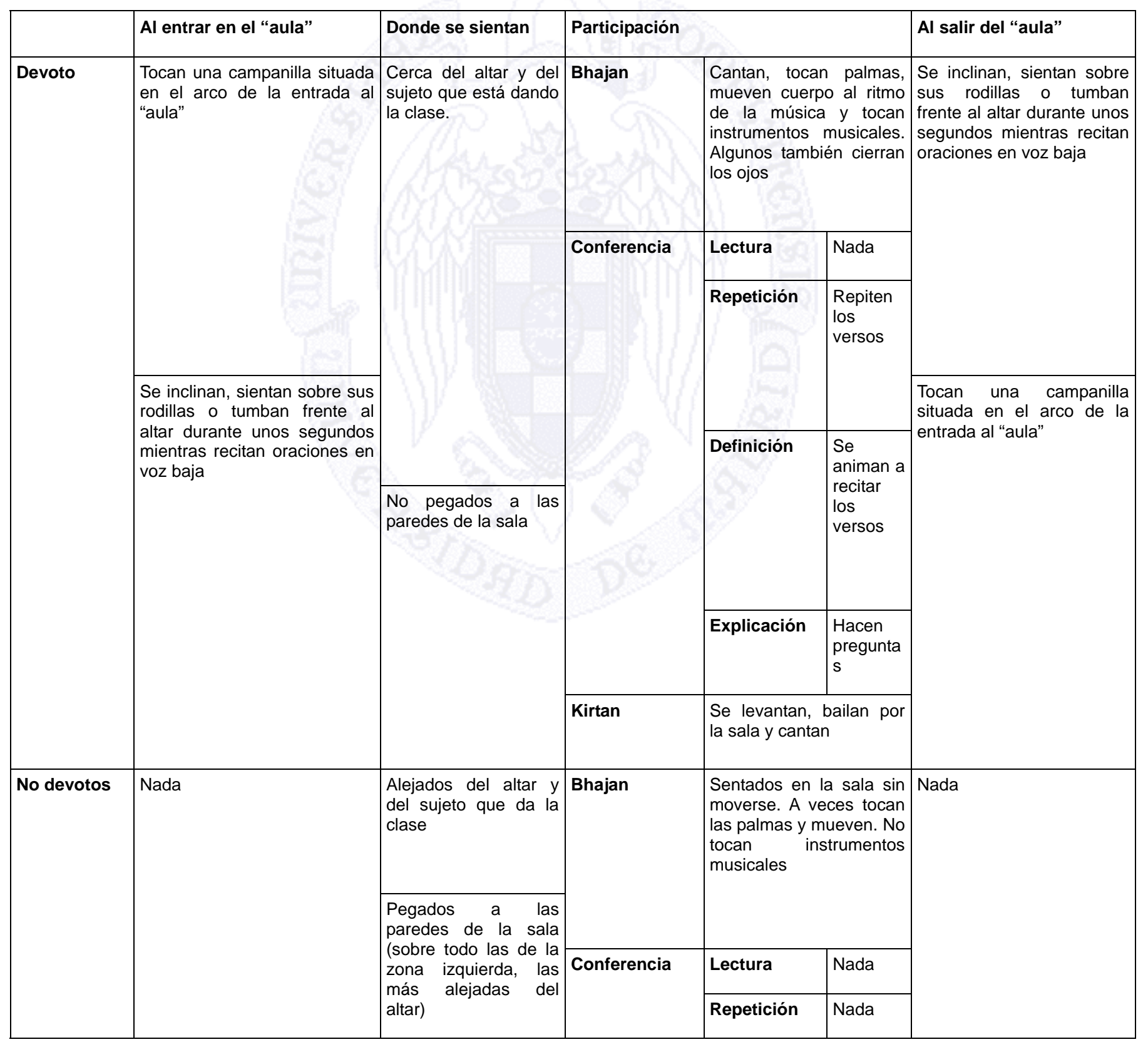




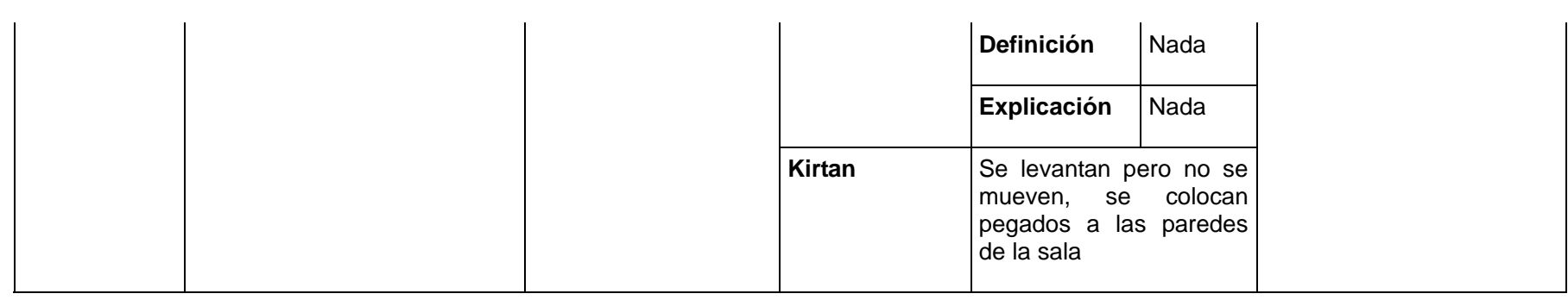

En esta tabla aparecen reflejados los comportamientos "típicos" de cada uno de las dos clasificaciones, si bien hay que entender que hay matices en tanto que cada sujeto se comporta de una manera distinta en cada momento concreto. Por ejemplo, en alguna observación de las clases de entre semana he observado a sujetos que podrían ser categorizados como no devotos - ellos mismos decían que era la primera vez que acudían al templo - y que, por otro lado, se sentaban cerca del altar y cantaba a viva voz en el Bhajan. Por otro lado, la forma de moverse difería con aquellos otros que he podido categorizar como devotos, en tanto que sus movimientos eran mucho más exagerados y llamativos (levantaban las manos o balanceaban mucho su cuerpo). Al mismo tiempo, también he observado a otros sujetos que según su comportamiento (en las actividades o al entrar en la sala) podrían ser considerados como devotos pero que se sentaban alejados del altar y pegados a la pared.

Por lo tanto, es importante tener en cuenta esta premisa de que cada sujeto más allá de que pueda ser incluido en una categoría - se comporta de una manera única.

Comenzando por el análisis de la tabla, puede observarse cómo el primer aspecto que llama la atención es el comportamiento que tienen los devotos y los no devotos al entrar en la sala.

Esta diferenciación se debe principalmente al sentido que los diferentes sujetos dan tanto al lugar en que se desarrollan las actividades como a las propias actividades.

Para los primeros (los devotos), el "aula" es un espacio sagrado, en el que se encuentra el altar y las deidades a las que adoran. Por lo tanto, el entrar en dicho espacio implica una serie de reglas y procedimientos que tienen como fin mostrarse como devoto y sirviente de Krishna. Por otro lado, los no devotos, al no profesar dicha religión ni conocer sus lógicas ni sus reglas sobre cómo mostrarse ante las deidades, simplemente entran en la sala y buscan un lugar para sentarse.

Respecto a este hecho de buscar un lugar para sentarse, en la tabla también pueden observase diferencias importantes entre devotos y no devotos.

Si volvemos a traer a colación la misma idea de que los devotos a priori entienden el lugar como un espacio de carácter religioso al que están más habituados a acudir y además estas clases les sirven para aumentar sus conocimientos sobre el culto $\mathrm{y}$, al mismo tiempo aproximarse a Krishna, es ciertamente lógico que intenten colocarse en un lugar cercano a lo que podría considerarse como el "epicentro" de la clase, que es el altar (porque en él están las deidades y por los ritos de adoración que se hacen durante el Kirtan) y el sujeto que de la clase (que son los poseen un mayor número de conocimientos religiosos y además a los que los devotos deben aproximarse con el fin de 
"progresar" dentro del culto, ya que ellos son los que miden el "progreso" y las intenciones de los devotos y los que, en última instancia, marcan el paso del mismo por los áshramas).

Por otro lado, los no devotos no suelen estar acostumbrados a acudir al templo, y por lo tanto las actividades que se realizan chocan podrían con su propia cotidianidad, de ahí que busquen colocarse en lugares apartados de ese "epicentro" con el fin de "no llamar la atención" o "no molestar".

Esta última idea se ve reflejada por ejemplo en la forma en que unos y otros (devotos y no devotos) hacen otro tipo de acciones complementarias en las clases como es el tomar fotos. Los devotos simplemente sacan la cámara y hacen la foto (o las fotos que sean) de manera pausada y tranquila, moviéndose libremente por la sala. Sin embargo, los no devotos intentan hacer las fotos de manera rápida, sin acercase a la zona del altar o, si lo hacen, intentando que sea lo más rápido posible, como si, de alguna manera, pudieran pensar que esa acción "rompe" con la propia religiosidad de la actividad.

Al mismo tiempo, esta distinción respecto al lugar que ocupan los sujetos en el espacio puede servir para ir observando la propia "evolución" interna de los sujetos con el culto religioso. Como se ha descrito, un sujeto ajeno al culto se comportará con cierto temor o miedo, y esa primera situación de incertidumbre y extrañeza se irá superando en tanto que se vaya integrando dentro del mismo y de sus lógicas. El desarrollar más profundamente estos procesos de conversión ciertamente se sale del interés del artículo y, además, ha sido tratado de manera profunda por otros autores (Prat, 2001; Vallverdú, 1999, 2001b); sin embargo es importante remarcar que, en la medida en que ese proceso de conversión se va llevando a cabo, la propia forma en la que los sujetos se van posicionando en el espacio va variando. De esa primera situación que podría incluso denominarse como incómoda, se va pasando a un acercamiento progresivo a esa otro modelo de comportamiento más propio de los devotos, en donde la propia intención personal de los sujetos tanto en las actividades como en el culto va cambiando. De ahí que a través de la propia observación del comportamiento interno pueda intuirse (hasta cierto punto) esa propia subjetividad de los sujetos.

Esta progresivo acercamiento e interés de unos determinados sujetos que en un principio puede ser categorizados como no devotos por el culto Hare Krishna a través del comportamiento que tienen en las actividades que se realizan en el templo, también guardan relación con la propia descripción del comportamiento durante las actividades.

Comparando ambas categorías, se observa cómo los no devotos tienen a tener un rol más pasivo (atendiendo a los patrones antes descritos como el sentido que le dan a las actividades frente a ese otro significado que construyen los devotos de las mismas) mientras que los devotos tienden a participar más. Incluso en aquellos comportamientos en los que pueden coincidir, el cómo son ejecutados puede servir como elemento diferenciador entre ambas categorías.

Por poner un ejemplo, durante los Bhajan, los movimientos que un devoto y un no devoto pueden coincidir (el dar palmas, o el moverse al son del ritmo). Sin embargo, la propia manera en que estos movimientos son realizados varían sustancialmente. Los devotos tienden a mantener una actitud de concentración constante en la actividad - ya que el cantar el santo nombre es una de las 
herramientas que tienen para conectar con Dios -, mientras que los no devotos realizan los gestos de manera discontinua $y$, en cierto grado, sin la misma concentración que la de los devotos - debido también a que el significado que dan a la misma actividad es distinta a la de un devoto - esto se manifiesta por ejemplo a cantos con una voz más baja, palmas más escuetas y sobre todo en miradas al resto de los asistentes a la sala, mientras que el volumen de los cantos y palmas que realizan los devotos son más altos y al mismo tiempo su mirada se centra de manera continua en el altar o en el sujeto que da la clase o, por otro lado, mantienen sus ojos cerrados mientras se mueven, cantan y tocan palmas.

También el hecho de que se toquen instrumentos musicales es un importante factor diferenciador, principalmente porque el hecho de tocarlos requiere conocer unos ritmos básicos al respecto, y también porque el hecho de tocar 0 no tocar instrumentos tiene que ver más con una decisión intencionada que toman los devotos más allá de una posible obligación que provenga, por ejemplo, del sujeto que esté dando la clase. Por ese motivo, no solo hay que entender el hecho de tocar los instrumentos como mero acompañamiento a los cantos, sino que los propios devotos depositan en ese acto unas determinadas intenciones, ideas y estados personales que guardan una estrecha relación con la idea de la purificación y el contacto con Krishna.

Este mismo análisis de la idea de las actividades como herramientas para conectar con Krishna que los devotos utilizan queda reflejado también en los diferentes comportamientos que cada una las dos categorías tiene, por ejemplo, durante el Kirtan.

Por lo tanto, podría decirse que esas diferentes formas de comportarse en la sala sirven para replantearse la existencia de diferentes categorías de sujetos que acuden a las actividades del templo que además están interconectadas a través de posibles subniveles de carácter totalmente subjetivo que estarían intrínsecamente relacionados como una parte de los procesos de conversión de los sujetos hacia la religión Hare Krishna.

Gracias a esta distinción entre devotos y no devotos, es posible comprender de manera más detallada y concisa por qué anteriormente planteé las diferentes categorizaciones etic de actividades que se dan en el templo. Aquellas actividades que he denominado "destinadas para devotos Hare Krishna" (cfr. 5.) estarían, en su mayoría, compuestas por sujetos que se comportarían dentro de la categoría de devotos, mientras que en las "clases destinadas a gente que no suele tener relación con el culto" (cfr. 6.) habría una gran cantidad de sujetos no devotos.

Ateniendo tanto al análisis estructural como a este análisis observacional del comportamiento, es posible justificar la citada diferenciación de actividades y, al mismo tiempo, explicar el por qué unas son utilizadas por un tipo de sujetos y no por otros. 


\section{CONCLUSIÓN}

Si bien en este artículo me he centrado en analizar unos aspectos concretos de lo que englobaría todo el trabajo de campo realizado, creo que es importante sacarlo a la luz no solo por lo planteado en el marco teórico, sino porque este tipo de estrategias forman parte de un proceso que he venido observando en el culto desde aproximadamente mediados del año 2012. Si bien en etapas anteriores mis propios informantes me llamaban la atención sobre la "fuerza" que habían perdido durante los últimos años (y que eso se manifestaba en las actividades que podían realizad), a partir de esos meses he podido ir percibiendo cómo se ha venido produciendo un cambio de mentalidad sin que necesariamente (según he observado) haya habido un cambio significativo en el número de devotos o de personas que acudan al templo.

Esta serie de cambios podrían encuadrarse en lo que he considerado como un proceso de "modernización" y "revitalización" del culto, que viene dado por una predisposición de esos mismos informantes a implicarse en proyectos de expansión del culto, como son la búsqueda de nuevos espacios tanto en la ciudad (templos) como en la periferia (la compra de un terreno en la provincia de Ávila para formar una comunidad rural) y a la promoción de nuevas actividades de carácter educativo en el mismo templo de Madrid -esas mismas actividades que no he analizado en este artículo según los criterios que expuse al comienzo del análisis- como son clases de yoga, clases de instrumentos musicales o reuniones de devotas. Por lo tanto, quizás en un futuro sea necesario complementar este artículo con esas nuevas estrategias educativas, según se vayan desarrollando y consolidando a lo largo del tiempo.

Al mismo tiempo, en este presente artículo me he centrado en determinadas actividades educativas de carácter informal que se dan en el templo de Madrid en el que he venido realizando mi principal trabajo de campo, creo que es interesante el hacer una breve mención otro tipo de "estrategias" educativas de carácter más institucionalizado y regulado.

Sin embargo, según he podido observar en el trabajo de campo estas otras formas educativas se imparten en ese otro espacio que ISKCON posee en Brihuega, Ilamado Nueva Vraja Mandala y renombrado hace aproximadamente un año como "Instituto de Estudios Bhaktivedanta España" (IEB). En este espacio, a parte de desarrollarse determinadas actividades de carácter devocional muy similares a las del templo de Madrid (pero con las particularidades propias como, por ejemplo, el sentido que le dan los devotos al mismo o el propio contexto del espacio, o el hecho de que normalmente no suela haber sujetos no devotos en dichas las actividades) ${ }^{20}$, también se plantean una oferta formativa de cursos (para residentes o no residentes, como un curso de Bhakti Satri ${ }^{21}$ ) y talleres sobre temáticas como la agricultura

20 A pesar de esas similitudes, también entre esas actividades que se dan en el templo de Madrid y en el de Brihuega existen grandes diferencias que atienden a esos factores y a muchos otros. Para explicarlo mejor sería necesario plantear un artículo en el que se comparen ambos espacios al tiempo que se explican y se da sentido al por qué de las diferencias.

21 El Bhakti Satri es el estudio de las escrituras divinas, y es otra de las formas por las que un devoto puede purificar su alma y acercarse a Dios. Según la página web del instituto, estas son las características del curso: "con una duración de 6 meses, este curso abarca el estudio de las principales Escrituras sagradas devocionales: Bhagavad Gita, Néctar de la Devoción, Sri Isopanisad y Upadesamrta. Está dirigido a estudiantes que hayan completado el 
ecológica, el Ayurveda, o la adoración de deidades. Todas estas actividades tienen fechas concretas y un programa detallado, al tiempo que también es necesario pagar para realizar muchas de ellas.

A raíz de esta otra "visión formalizada" de la propia enseñanza religiosa, resultaría también interesante plantear una comparación entre ambos tipos de educación, encuadrándolas dentro de este proceso de cambio y evolución descrito, ya que queda patente que la propia educación en materia religiosa que, en este caso, pone de manifiesto el culto Hare Krishna, es un objeto de estudio que abarca un sin fin de posibilidades analíticas, y desde el cuál además se pueden abordar otras dimensiones culturales y religiosas que, si bien en este artículo se han mencionado pero no se han tratado debido a la concreción y extensión del mismo, quedan patentes después del análisis realizado.

\section{BIBLIOGRAFÍA}

Ardèvol, Elisenda; Muilla, Glòria (Coords.)

- 2003 Antropología de la religión, una aproximación interdisciplinar a las religiones antiguas y contemporáneas, Barcelona, UOC.

Ayala, Ariadna; García García, Sergio

- 2009 Gestión de cuerpos y actuación de resistencias en una política social. La aplicación de la Renta Mínima de Inserción en la Comunidad de Madrid, en Revista de Antropología experimental, 9: 17-36.

Balandier, Georges

- 1994 El poder de las escenas, Barcelona, editorial Paidós.

Burke Rochford, E.

- 2007 Hare Krishna Transformed, New York, New York University Press.

Canton, Manuela

- 2009 La razón hechizada: teorías antropológias dela religión, Barcelona, Akal.

Contretas Mazarío, Jose María

- 2011 Marco jurídico del factor religioso en España, Observatorio del Pluralismo Religioso en España

Contreras Hernández, Jesús; Gracia Arnáiz, Mabel

curso de Introducción al Bhakti Yoga, devotos/as que están familiarizados en los principios, la filosofía, y las prácticas de la Conciencia de Krishna, y/o que necesiten formarse para recibir la segunda iniciación (Brahmínica), y/o que deseen prepararse como profesores de las Escrituras." (IEB) 
- 2005 Alimentación y cultura, perspectivas antropológicas, Barcelona, Ariel.

Daner, Francine Jeanne

- 1976 The American Children of Krsna, New York, Harcourt School Publishers.

Dietz, Gunther

- 2008 La educación religiosa en España: ¿contribución al diálogo intercultural o factor del conflicto entre religiones?, Revista Estudios sobre las Culturas Contemporaneas, Vol. XIV, Núm. 28: 11-46.

Dowtown, James V.

- 1980 An evolutionary Theory of Spiritual Conversion and Commitment: The case of Divine Light Mission, Journal for the Scientific Study of Religion, 19(4): 381-396.

Geertz, Clifford

- $\quad 2005$ La interpretación de las culturas. Barcelona: editorial Gedisa.

Giroux, Henry

- $\quad$ 1985. Teorías de la reproducción y la resistencia en la nueva sociología de la educación: un análisis crítico. Cuadernos Políticos, 44: 36-65.

Hare Krishna Madrid

- $\quad$ Recurso electrónico, página Web del templo Hare Krishna de Madrid: www.harekrisnamadrid.com

Heelas, Paul

- 1996 The New Age Movement: The Celebration of the Self and the Sacralization of Modernity, Blackwell Publishers

Heelas, Paul y Woodhead, Linda

- 2000 Religion in Modern Times: An Interpretive Anthology. WileyBlackwell Publishers.

IEB

- $\quad$ Recurso electrónico, página Web del Instituto de Estudios Bhaktivedanta España: http://www.iebhaktivedanta.es

Morris, Brian

- 1987 Anthropological Sutidies of Religion: an introductory text, Cambridge University Press

- 2009 Religión y Antropología: una introducción crítica, Madrid, editorial Akal.

Lahire, Bernard

- 2004 El hombre plural: los resortes de la acción, Barcelona, Bellaterra.

López García, Bernabé / Ramírez Fernández, Ángeles / Herrero Galiano, Eva / Kirhlani, Said / Tello Weiss, Mariana. 
- 2007 Arraigados: minorías religiosas en la comunidad de Madrid, Icara y Pluralismo y Convivencia.

Prat, Joan

- 2001 El estigma del extraño: un ensayo antropológico sobre sectas religiosas, Barcelona, Ariel.

Rambo, Lewis R.

1999 Theories of Conversion: Understanding and Interpreting Religious Change, Social Compass 46(3): 259-271.

Vallverdú. Jaume

- 1999 Conversión, compromiso y construcción de identidad en el movimiento Hare Krishna, México, Revista Alteridades 9(18): 57-70.

- 2001 El cant de la devoció: un estudi antropològic sobre els Hare Krishna, Tarragona, Arola Editors.

- $\quad 2001$ b Mercado religioso y movimientos carismáticos en la modernidad en Gazeta de Antropología, 17: artículo 22.

Willis, Paul

- $\quad$ 1988. Aprendiendo a trabajar; Editorial Akal, Madrid

- 1993 "Producción cultural no es lo mismo que reproducción cultural, que a su vez no es lo mismo que reproducción social, que tampoco es lo mismo que reproducción", en Honorio M. Velasco, Javier García Castaño y Ángel Díaz de Rada (Eds.), Lecturas de antropología para educadores, Madrid: Trotta: 431461.

Wolcott, Harry F.

- $\quad 1993$ "El maestro como enemigo", en Honorio M. Velasco, Javier García Castaño y Ángel Díaz de Rada (Eds.), Lecturas de antropología para educadores, Madrid: Trotta: 243-258. 